\title{
Evaluation of different analytical methods to assess failure of passive transfer in neonatal calves
}

\author{
F. Sutter, ${ }^{1}$ E. Rauch, ${ }^{2} \odot$ M. Erhard, ${ }^{2}$ R. Sargent, ${ }^{3}$ C. Weber,,${ }^{4} \odot$ W. Heuwieser, ${ }^{1 *}{ }^{1}$ and S. Borchardt ${ }^{1} \odot$ \\ ${ }^{1}$ Clinic for Animal Reproduction, Faculty of Veterinary Medicine, Freie Universität Berlin, Koenigsweg 65, 14163 Berlin, Germany \\ ${ }^{2}$ Department of Veterinary Sciences, Chair of Animal Welfare, Ethology, Animal Hygiene and Animal Husbandry, Faculty of Veterinary Medicine, \\ LMU Munich, Veterinärstraße 13, 80539 Munich, Germany \\ ${ }^{3}$ Saskatoon Colostrum Co. Ltd., 30 Molaro Place, Saskatoon, SK, S7K 6A2, Canada \\ ${ }^{4}$ Laboklin GmbH \& Co. KG, Laboratory for Clinical Diagnostics, Steubenstraße 4, 97688 Bad Kissingen, Germany
}

\section{ABSTRACT}

The objective of this study was to evaluate different analytical methods of assessing failure of passive transfer (FPT) in neonatal calves. We hypothesized that 3 different media (i.e., centrifuged serum, centrifuged plasma, filtered plasma) and different analytical methods [i.e., ELISA, capillary electrophoresis (CE), Brix refractometer, and handheld optical refractometer] would be highly correlated with the gold standard radial immunodiffusion (RID) and would generate comparable results. Serum and plasma blood samples were collected from Holstein Friesian calves $(\mathrm{n}=216)$ aged 1 to $7 \mathrm{~d}$, from 2 commercial dairy herds in northeast Germany. The RID analysis showed that 59 of 216 calves (27\%) had serum IgG concentrations of $<10 \mathrm{mg} / \mathrm{mL}$ and 157 calves $(73 \%)$ had serum concentrations of $\geq 10 \mathrm{mg} / \mathrm{mL}$. The mean IgG concentration ( \pm standard deviation) was $17.1 \pm 9.8 \mathrm{mg} / \mathrm{mL}$, and the range was 0.8 to 47.8 $\mathrm{mg} / \mathrm{mL}$. In serum, the correlation between RID and CE was $r=0.97$, and between RID and ELISA was $r=0.90$; $\mathrm{CE}$ and ELISA were also highly correlated $(\mathrm{r}=0.89)$. Both refractometry methods were highly correlated with RID using centrifuged serum, centrifuged plasma, or filtered plasma (Brix refractometer: $\mathrm{r}=0.84,0.80$, and 0.78 , respectively; handheld optical refractometer: $\mathrm{r}=0.83,0.81$, and 0.80 , respectively). We determined test characteristics (optimum thresholds, sensitivity, specificity, positive predictive value, negative predictive value, and area under the curve) for CE, ELISA, and the handheld optical and digital refractometers using receiver operating characteristic curve analyses with RID as the reference value. Optimal thresholds for assessing FPT using plasma were higher than for serum, regardless of the method of plasma harvesting. The 4 different devices had comparable areas under the curve,

Received November 18, 2019

Accepted February 4, 2020.

*Corresponding author: w.heuwieser@fu-berlin.de irrespective of the medium used. All analytical methods can be used to assess FPT.

Key words: capillary electrophoresis, plasma filter, failure of passive transfer, neonatal calves

\section{INTRODUCTION}

An adequate colostrum supply is beneficial for the health of neonatal calves (Cuttance et al., 2018; Lora et al., 2018). It positively affects calves' metabolism can influence their lifetime performance as a dairy cow (Faber et al., 2005; Soberon et al., 2012; Soberon and Van Amburgh, 2013). Inadequate colostrum supply can be linked with decreased milk yield and increased culling rates during the first lactation (Chuck et al., 2018).

The timely delivery of appropriate quantities of highquality colostrum is necessary for the high absorption of intestinal IgG, which is essential for successful passive transfer of immunity in neonatal dairy calves (Weaver et al., 2000; Godden et al., 2009; Godden, 2017; Kertz et al., 2017). Sufficient maternal IgG supply via colostrum is crucial, because during gestation, the bovine epitheliochorial placenta impedes the transfer of $\operatorname{IgG}$ from the dam to the fetus. To acquire passive immunity, the neonatal calf depends on the absorption of maternal IgG from colostrum across the small intestinal epithelial cells before cessation of intestinal transport 24 to $36 \mathrm{~h}$ after birth (Weaver et al., 2000; Barrington and Parish, 2001). The absorption of maternal IgG is influenced by many factors, including the timing of the first feeding (Besser et al., 1985), the volume of colostrum fed (Stott et al., 1979a), and the quality of the colostrum (Pritchett et al., 1991). Good-quality colostrum has an IgG concentration $\geq 50 \mathrm{~g} / \mathrm{L}$, and total bacterial and fecal coliform counts that do not exceed 100,000 and 10,000 $\mathrm{cfu} / \mathrm{mL}$, respectively (Weaver et al., 2000; McGuirk and Collins, 2004; Godden, 2008). Therefore, the absorption of maternal IgG also depends on the conditions from which the colostrum is collected and stored (Weaver et al., 2000; Godden, 2008), on the 
apparent efficiency of absorption (Stott et al., 1979b; Rajala and Castren, 1995), and on the abomasal emptying rate (Mokhber-Dezfooli et al., 2012).

Insufficient absorption of maternal IgG, or failure of passive transfer (FPT), is defined as a serum IgG concentration of $<10 \mathrm{mg} / \mathrm{mL}$ in neonatal calves aged 24 to 48 h (Weaver et al., 2000; Godden, 2008). In addition to serum samples, other media such as centrifuged plasma or filtered plasma are appropriate for the assessment of FPT (da Costa Corrêa Oliveira et al., 2019; Elsohaby et al., 2019). The advantage of using filtered plasma to assess FPT is that a large number of blood samples can be collected and analyzed without the need for centrifugation (da Costa Corrêa Oliveira et al., 2019). In this way, regular assessment of FPT could be integrated into the daily work routine of a dairy farm. Different studies have used either serum or plasma samples to assess FPT, or they have directly compared the 2 media in a small number of samples (MacFarlane et al., 2014; Villarroel et al., 2014). Elsohaby et al. (2019) and da Costa Corrêa Oliveira et al. (2019) have published the first studies directly comparing serum and plasma samples from the same dairy calves using a larger sample size $(\mathrm{n}=217$ and 227 , respectively).

Radial immunodiffusion (RID) is the gold standard for assessing serum IgG concentrations in neonatal calves (Bielmann et al., 2010). Laboratory-based methods such as RID and ELISA are technically demanding and require trained laboratory technicians to conduct them (Davis and Giguère, 2005; Hogan et al., 2015). The measurement of serum total protein (TP) using refractometry is a simple alternative for indirectly assessing serum IgG concentration, because TP represents the concentration of immunoglobulins (Calloway et al., 2002; Bielmann et al., 2010; Deelen et al., 2014; Buczinski et al., 2018). Refractometry can be performed using optical devices that measure TP concentration $(\mathrm{g} / \mathrm{dL})$ or digital Brix refractometers that evaluate total solids (TS) using the refractive index (Brix percentage). Both methods of refractometry are highly correlated with IgG concentration as determined by RID, if calves are tested between $24 \mathrm{~h}$ and $7 \mathrm{~d}$ of age (McGuirk and Collins, 2004; Deelen et al., 2014; Buczinski et al., 2018). Thresholds used to identify calves with successful passive transfer range from 4.6 to $5.8 \mathrm{~g} / \mathrm{dL}$ TP in serum (Lee et al., 2008; McCracken et al., 2017) and from 7.1 to $8.8 \%$ Brix (Cuttance et al., 2017; McCracken et al., 2017). According to McGuirk and Collins (2004), successful passive transfer is acquired at $\geq 5.2 \mathrm{~g} / \mathrm{dL}$ serum $\mathrm{TP}$ in healthy calves or $\geq 5.5 \mathrm{~g} / \mathrm{dL}$ in ill calves. Using herd-based testing to monitor passive transfer, a minimum of 12 calves should be tested. Adequate colostrum management results in $80 \%$ of calves with $\geq 5.5 \mathrm{~g} / \mathrm{dL}$ serum TP (McGuirk and Collins, 2004). If more than $20 \%$ of calves have lower serum TP levels, the herd is at risk for a problem with FPT. Using a digital Brix refractometer for FPT assessment, the cutoff is $8.4 \%$ Brix (Deelen et al., 2014).

Capillary electrophoresis (CE) is an analytical method based on the movement of charged particles in a liquid medium under the influence of an electric field. The migration velocities of different particles depend on their charge, shape, and size, as well as on the solution environment and the strength of the electric field. Different particles are separated during migration. In $\mathrm{CE}$, this separation takes place in a capillary tube using an electrolyte solution. In human medicine, $\mathrm{CE}$ and capillary gel electrophoresis (CGE) are well established, common methods used for protein separation (Zhu et al., 2012). In contrast to CE, CGE uses a gel medium for separation (Bennett et al., 1994). In bovine veterinary medicine, $\mathrm{CE}$ and $\mathrm{CGE}$ are rarely used for protein and $\operatorname{IgG}$ analysis, although protein analysis by CGE has been successfully used to measure bovine IgG concentrations (Bennett et al., 1994). Nevertheless, CE and CGE have not been validated for the assessment of FPT in neonatal calves.

The objective of this study was to evaluate different analytical methods of assessing FPT in neonatal calves. We hypothesized that 3 different media (i.e., centrifuged serum, centrifuged plasma, filtered plasma) and different analytical methods (i.e., ELISA, CE, Brix refractometer, and handheld optical refractometer) would be highly correlated with the gold standard RID and generate comparable results.

\section{MATERIALS AND METHODS}

\section{Dairy Farm, Animal Enrollment, and Sample Collection}

The study was conducted from August to October 2018 on 2 commercial farms in northeast Germany. Because all of the required material to monitor FPT was obtained during routine farm-management practices, the study was in accordance with requirements of the Institutional Animal Care and Use Committee of the Freie Universität Berlin. We performed a sample-size calculation as described by Moinester and Gottfried (2014) for different half-widths (w) and Pearson correlation coefficients ( $\mathbf{r}$ ), based on CIxcorr, expecting the desired $95 \%$ confidence interval (CI). Clxcorr is an $\mathrm{R}$ function that determines the CI for given Pearson correlation coefficients, calculating lower and upper levels, widths for the CI, significance $(\alpha)$, and sample size (Moinester and Gottfried, 2014). For $\mathrm{r}=0.80$ and $\mathrm{w}=0.05$, we needed a sample size of 205 . 
Clinically healthy Holstein Friesian calves $(\mathrm{n}=216)$ were enrolled in the study between $24 \mathrm{~h}$ and $7 \mathrm{~d}$ of age. New intake of calves took place weekly, and we obtained relevant calf data such as date and time of parturition, sex, twin birth, colostrum uptake, and identification number from the on-farm documentation. Calves were considered clinically healthy if no visible signs of disease were observed. Calves with diarrhea, pneumonia, or dehydration were rejected from the study. Diarrhea was defined as visibly loose feces of decreased consistency. Pneumonia was defined as visibly detectable tachypnea with nasal discharge (serous, mucous, or purulent), and dehydration was defined as reduced skin turgor.

Whole blood of calves was collected by jugular venipuncture using a 20-gauge, 1.0-inch needle (Vacuette 20 $\times 1$ sterile cannula; Greiner Bio-One GmbH, Kremesmünster, Austria) and 2 sterile plastic evacuated tubes: one without anticoagulant $(9 \mathrm{~mL}$, Vacuette CAT Serum; Greiner Bio-One $\mathrm{GmbH}$ ) and one with lithium heparin (9 mL, Vacuette LH; Greiner Bio-One GmbH). Serum samples were centrifuged at 4,500 $\times g$ for 6 min at approximately $20^{\circ} \mathrm{C}$ on the farm 1 to $2 \mathrm{~h}$ after collection and were directly assessed using a handheld optical refractometer (RF.5612 Handheld; Euromex Holland, Arnhem, the Netherlands) and a digital Brix refractometer (Misco PA201; Misco, Solon OH). Plasma filtration and plasma centrifugation were carried out at approximately $20^{\circ} \mathrm{C}$ in the laboratory of the Clinic for Animal Reproduction, Faculty of Veterinary Medicine, Freie Universität Berlin, $6 \mathrm{~h}$ after sample collection. For transportation to the laboratory, all samples were stored on ice.

Filtered plasma obtained through a disposable filter been validated as an analytical medium for FPT assessment in dairy calves using refractometry (da Costa Corrêa Oliveira et al., 2019). Before plasma filtration, each lithium heparin sample was swiveled using a roll mixer for blood samples (RS-TR 5; Phoenix Instrument, Garbsen, Germany) for $10 \mathrm{~min}$. Using a disposable syringe $(5 \mathrm{~mL}$ HS Luer sterile disposable syringe; Henry Schein, Langen, Germany), $2 \mathrm{~mL}$ of lithium heparin blood was aspirated and injected into the inlet reservoir of a plasma filter (2-Drop-Filter; Pharmadoc, Lübeck, Germany), which generated 2 drops of plasma. For each measurement, a new filter was used. Then, the lithium heparin blood samples were centrifuged at $4,500 \times g$ for 6 min to obtain plasma.

To evaluate FPT on farm, all of the samples (i.e., centrifuged serum and filtered and centrifuged plasma) were assessed using a digital Brix refractometer (Brix percentage; Misco PA201; Misco) and a handheld optical refractometer (TP, g/dL; RF.5612 Handheld; Euromex Holland). Both refractometers are optical devices built to analyze the concentration of water- soluble solids, generating a refractive index. The digital Brix refractometer also assesses the speed at which the emitted beam of light passes through the fluid. At high densities, light passes more slowly through the fluid. Both devices have automatic temperature calibration, so that accurate measurements are possible between 0 and $50^{\circ} \mathrm{C}$ (Misco PA201), and 0 and $30^{\circ} \mathrm{C}$ (RF.5612 Handheld). Before each batch of samples was evaluated, the devices were calibrated with distilled water at room temperature $\left(20^{\circ} \mathrm{C}\right)$.

Four aliquots of serum and 1 aliquot of centrifuged plasma were collected for further analysis. To obtain the aliquots, $1.5 \mathrm{~mL}$ of serum or plasma were pipetted into a sterile vial (Cryovial $2 \mathrm{~mL}$; Simport, BernardPilon, Germany). One serum aliquot was sent frozen to the Department of Veterinary Science, Chair of Animal Welfare, Ethology, Animal Hygiene and Animal Husbandry (Faculty of Veterinary Medicine, LMU Munich, Germany) for IgG testing using sandwich ELISA according to Erhard et al. (1999). One serum aliquot was sent to an accredited commercial laboratory (Laboklin, Bad Kissingen, Germany; accreditation number: DIN EN ISO IEC 17025:2005) to assess IgG concentration via CE. A third serum aliquot was sent to the Saskatoon Colostrum Co. Ltd. in Canada for IgG assessment using single RID.

\section{Serum and Plasma Sample Analyses}

At the Department of Veterinary Science in Munich, IgG concentrations were assessed by sandwich ELISA. The method was based on coating and conjugating rabbit anti-bovine IgG coupled to a peroxidase enzyme (A 5295; Sigma-Aldrich Chemie GmbH, Taufkirchen, Germany) with the calves' serum IgG. Proportional to the IgG concentration of the sample, the peroxidase enzyme induced a color change, which could be quantified photometrically at $450 \mathrm{~nm}$ using an ELISA reader (GENios; Tecan Germany GmbH, Crailsheim, Germany). Serum samples were diluted with PBS-Tween at a ratio of 1:10,000 ( $\mathrm{vol} / \mathrm{vol}$ ). Rabbit serum with anti-bovine IgG $(5 \mu \mathrm{g} / \mathrm{mL}$; A 5645; Sigma-Aldrich Chemie GmbH) was pipetted into each well of a 96-well polystyrene plate (F96 Cert. Maxisorp Nunc-Immuno Plate, Thermo Scientific GmbH, Darmstadt, Germany) and blocked with a $0.5 \%$ gelatin PBS solution. The serum samples were inserted at the uppermost well of each column and diluted using a 2-logarithmic dilution series with PBS-Tween buffer. Then, the peroxidase-linked rabbit anti-bovine IgG was pipetted into each well and the substrate solution $(332 \mu \mathrm{L}$ of stock solution, $10 \mathrm{~mL}$ of $3,3^{\prime}, 5,5^{\prime}$-tetramethylbenzidine-buffer, and $30 \% \mathrm{H}_{2} \mathrm{O}_{2}$ ) was added. After the enzyme reaction took place, 50 $\mu \mathrm{L}$ of $1 M$ sulfuric acid was applied to stop the reaction 
process, and photometric intensity was measured. The final $\mathrm{IgG}$ concentration $(\mathrm{mg} / \mathrm{mL})$ of each serum sample was determined by the mean value of each column.

For CE analysis, serum samples were diluted with $\mathrm{NaCl}$ 0.9\% (B. Braun Melsungen AG, Melsungen, Germany) at a ratio of $1: 2(\mathrm{vol} / \mathrm{vol})$. Silica capillaries were the main component of the CE apparatus (Minicap Immunotyping; Sebia SA, Lisses, France). In these silica capillaries, serum proteins were separated by their electrophoretic mobility and electro-osmotic flow at high voltage on the anode or cathode in an alkaline buffer. The use of quartz capillaries enabled UV detection, whereby proteins were directly detected during migration by UV absorbance. This process generates different concentration peaks that represent the concentration of the various protein components. The $\gamma$-globulin peak can be clearly separated from other peaks, and it consists mainly of $\mathrm{IgG}$. The relative IgG concentration obtained by $\mathrm{CE}$ was recalculated using the TP concentration determined by a modular analyzer (Cobas c701 module; Roche Diagnostics Deutschland GmbH, Mannheim, Germany). This method was validated internally in the accredited commercial laboratory (Laboklin) with an intra-assay coefficient of variation (CV) of $<6.4 \%$, and an inter-assay CV of $<6.3 \%$.

Radial immunodiffusion was performed as described by Chelack et al. (1993). The single RID plates contained agarose gel with incorporated anti-bovine IgG (Bethyl Laboratories Inc., Montgomery, TX). Wells of $2 \mathrm{~mm}$ were punched out of the agarose gel. Serum samples and a reference serum were applied in serial dilutions with PBS-Tween buffer into the wells of the RID plates, from where they enter circularly into the gel via diffusion. The resulting immunoprecipitin ring diameters were measured using an imaging analyzer, and a standard curve was generated using the reference serum. The IgG concentration of the serum samples was determined by regressing the immunoprecipitin ring diameters on the standard curve. If the IgG concentration of a sample was outside the lowest or highest standard sera, the sample was retested at a lower or higher dilution that would place it within the range of the standards. This method has been validated internally in the Saskatoon Colostrum Co. Ltd. with an intra-assay CV of 2.1\% (216 samples), and an interassay CV of $7.2 \%$ (54 RID plates), respectively.

\section{Data Collection and Statistical Analyses}

The findings for $\mathrm{TP}(\mathrm{g} / \mathrm{dL})$ and Brix (\%) from centrifuged serum and centrifuged or filtered plasma were plotted against the IgG concentrations $(\mathrm{mg} / \mathrm{mL})$ obtained by RID. Furthermore, the IgG concentrations obtained by ELISA and CE were plotted against the those obtained by RID. Pearson correlation coefficients (r) were determined using these distribution plots. Correlation coefficients and Bland-Altman plots were generated using Excel 2010 (Microsoft Deutschland Ltd., Munich, Germany). The Bland-Altman plot was used to quantify the agreement between 2 quantitative measurements by using statistical limits of agreement, which we calculated using the mean and standard deviation (SD) of the differences between the 2 measurements (Bland and Altman, 1999, 2003). The quantitative difference of the 2 measurements were plotted against the average of the 2 measurements (RID and ELISA; RID and CE). The limits of agreement were expressed as the mean difference $\pm 1.96 \mathrm{SD}$ (Bland and Altman, 1999, 2003). By definition, 95\% of the data points lie within $\pm 1.96 \mathrm{SD}$ of the mean difference. The limits of agreement should be discussed in light of their clinical relevance.

For the different media, we calculated the average IgG concentrations (means $\pm \mathrm{SD}$ ) and test characteristics [sensitivity (Se), specificity (Sp), positive predictive value, negative predictive value, area under the curve (AUC)] using MedCalc (version 15.6.1; MedCalc, Mariakerke, Belgium). Sensitivity described the probability that a test result correctly indicated FPT for a sample with $\operatorname{IgG}<10 \mathrm{mg} / \mathrm{mL}$. Specificity described the probability that a test result correctly indicated successful passive transfer for a sample with $\operatorname{IgG} \geq 10 \mathrm{mg} / \mathrm{mL}$. Positive predictive value described the predictive probability that a test result would correctly indicate FPT for a sample with $\operatorname{IgG}<10 \mathrm{mg} / \mathrm{mL}$. Negative predictive value described the predictive probability that a test result would correctly indicate successful passive transfer for a sample with $\operatorname{IgG} \geq 10 \mathrm{mg} / \mathrm{mL}$.

By plotting the true positive rate against the false positive rate in increments of $0.1 \mathrm{~g} / \mathrm{dL}$ and $0.1 \%$ Brix, we generated a receiver operating characteristic curve and assessed the optimal thresholds. The optimal threshold was defined as the point on the curve with the highest combined Se and Sp, and its deduction was based on the AUC according to Swets (1988) as perfect $(\mathrm{AUC}=1)$, highly accurate $(0.9<\mathrm{AUC}<1)$, very accurate $(0.7<$ AUC $<0.9)$, accurate $(0.5<$ AUC $<0.7)$, and noninformative $(\mathrm{AUC}=0.5)$. Differences were considered significant at $P<0.05$; a statistical tendency was specified as differences between $P \geq 0.05$ and $P \leq 0.10$.

\section{RESULTS}

\section{Descriptive Statistics}

The RID analysis indicated that 59 of 216 calves (27\%) had serum IgG concentrations $<10 \mathrm{mg} / \mathrm{mL}$, and 
Table 1. Descriptive statistics for Brix percentage, total protein (TP), and IgG concentration from centrifuged serum, centrifuged plasma, and filtered plasma $(\mathrm{n}=216)$

\begin{tabular}{|c|c|c|c|c|}
\hline Method and medium & Measure & Mean \pm SD & Minimum & Maximum \\
\hline \multicolumn{5}{|c|}{ PA 201 Misco Brix refractometer ${ }^{1}$} \\
\hline Centrifuged serum & Brix $(\%)$ & $8.2 \pm 0.78$ & 6.6 & 11.1 \\
\hline Centrifuged plasma & Brix $(\%)$ & $9.0 \pm 0.81$ & 7.2 & 11.8 \\
\hline Filtered plasma & Brix $(\%)$ & $9.1 \pm 0.84$ & 7.3 & 11.8 \\
\hline \multicolumn{5}{|c|}{ Handheld optical refractometer } \\
\hline Centrifuged serum & $\mathrm{TP}(\mathrm{g} / \mathrm{dL})$ & $5.3 \pm 0.64$ & 4.0 & 7.4 \\
\hline Centrifuged plasma & $\mathrm{TP}(\mathrm{g} / \mathrm{dL})$ & $5.9 \pm 0.66$ & 4.5 & 8.0 \\
\hline Filtered plasma & $\mathrm{TP}(\mathrm{g} / \mathrm{dL})$ & $5.9 \pm 0.68$ & 4.4 & 8.4 \\
\hline \multicolumn{5}{|l|}{ Sandwich ELISA } \\
\hline \multirow{2}{*}{\multicolumn{5}{|c|}{ Capillary electrophoresis }} \\
\hline & & & & \\
\hline Centrifuged serum & $\operatorname{IgG}(\mathrm{mg} / \mathrm{mL})$ & $11.0 \pm 5.72$ & 1.2 & 32.9 \\
\hline \multicolumn{5}{|l|}{ Radial immunodiffusion } \\
\hline Centrifuged serum & $\operatorname{IgG}(\mathrm{mg} / \mathrm{mL})$ & $17.1 \pm 9.77$ & 0.8 & 47.8 \\
\hline
\end{tabular}

${ }^{1}$ Misco (Solon, OH).

157 calves $(73 \%)$ had serum $\operatorname{IgG}$ concentrations $\geq 10$ $\mathrm{mg} / \mathrm{mL}$. The mean IgG concentration was $17.1 \pm 9.8$ $\mathrm{mg} / \mathrm{mL}$, and the range was 0.8 to $47.8 \mathrm{mg} \mathrm{IgG} / \mathrm{mL}$. Descriptive statistics for the different devices and media are listed in Table 1.

\section{Correlation Coefficients and Bland-Altman Plots}

The Pearson correlation coefficients for serum RID and ELISA, and for RID and CE, were 0.90 and 0.97, respectively (Figure 1); CE and ELISA were also highly correlated $(\mathrm{r}=0.89)$. Both refractometry methods (handheld optical and digital Brix refractometer) were highly correlated with RID using centrifuged serum, centrifuged plasma, or filtered plasma; the range of correlation coefficients was 0.78 to 0.84 (Figure 2 and 3). Among themselves, the refractometry methods generated highly correlated results, irrespective of the medium: the range of correlation coefficients was 0.92 to 0.99 .

The Bland-Altman plots comparing the measurement of $\operatorname{IgG}$ concentrations in the serum of calves using RID and ELISA, and RID and CE, are shown in Figure 4. On average, IgG concentrations as measured by RID were $8.6 \mathrm{mg} / \mathrm{mL}$ higher than those measured by ELISA, and $6.1 \mathrm{mg} / \mathrm{mL}$ higher than those measured by CE. The limits of agreement were -3.3 and 20.4 $\mathrm{mg} / \mathrm{mL}$ for ELISA, and -2.6 and $14.9 \mathrm{mg} / \mathrm{mL}$ for CE. However, we found a systematic bias in the difference between RID and ELISA, as well as between RID and $\mathrm{CE}$, and the mean $\operatorname{IgG}$ concentration.

\section{Test Characteristics}

Receiver operating characteristic curve analyses using RID as the reference value generated the test char- acteristics (optimal thresholds, Se, Sp, positive predictive value, negative predictive value, and $\mathrm{AUC}$ ) for $\mathrm{CE}$, ELISA, and refractometry for identifying calves with FPT using 3 different media (Table 2). The analyses for ELISA showed that the optimal threshold was 5.4 mg IgG/mL (Se 94.9\%, Sp 97.5\%, AUC 0.99; Table 2). For CE, the optimal threshold was $6.9 \mathrm{mg} \mathrm{IgG/mL} \mathrm{(Se}$ 94.9\%, Sp 98.7\%, AUC 0.99; Table 2).

Optimal thresholds for assessing FPT using plasma were higher than those for serum, regardless of the method of plasma extraction. The 4 different devices had comparable AUC, irrespective of the medium used.

\section{DISCUSSION}

The principal findings of this study were that the 4 different analytical methods of assessing FPT (i.e., ELISA, CE, Brix refractometer, and handheld optical refractometer) were highly correlated with the gold standard RID and had a comparable AUC. Furthermore, all 3 different media (i.e., centrifuged serum, centrifuged plasma, and filtered plasma) had highly accurate AUC results and were highly correlated with RID. As well, the optimal thresholds for FPT using plasma were higher than those for serum, regardless of the method of plasma extraction.

\section{Correlation Coefficients and Bland-Altman Plots}

In serum, the correlation coefficients between the laboratory methods RID, ELISA, and CE were high ( $\mathrm{r}$ $=0.90,0.97)$. This was in agreement with the findings of previous studies (Lee et al., 2008; Dunn et al., 2018). In particular, a study by Bennett et al. (1994) reported a high correlation coefficient $(\mathrm{r}=0.99)$ by plotting bovine IgG against molecular weight standards assessed 
a)

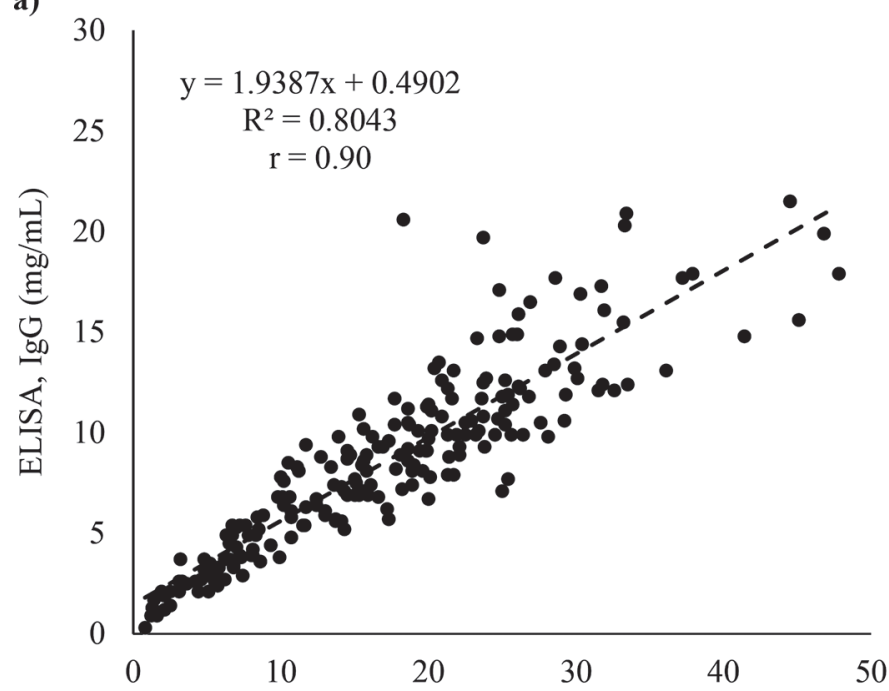

b)

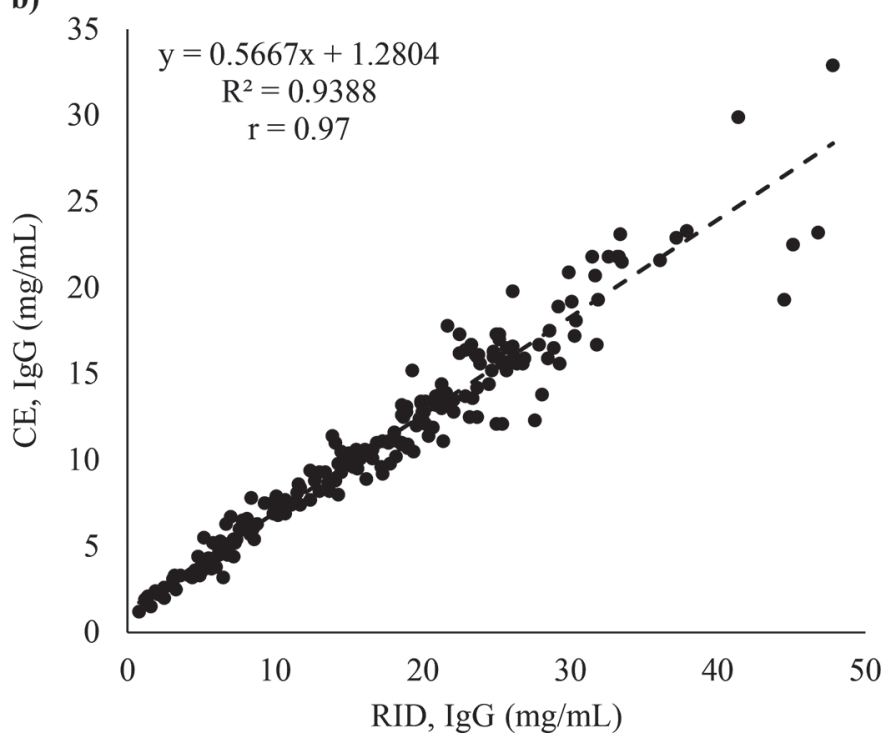

Figure 1. Concentration of IgG in the centrifuged serum of calves assessed with radial immunodiffusion (RID) compared with (a) ELISA $(\mathrm{n}=216 ; \mathrm{r}=0.90)$, and (b) capillary electrophoresis $(\mathrm{CE} ; \mathrm{n}=216$ $\mathrm{r}=0.97)$

by CE. Gelsinger et al. (2015) reported a weaker but still significant relationship between a modified ELISA (Bethyl Laboratories) and a commercially available single RID assay (Triple J Farms, Bellingham, WA) using plasma $\operatorname{IgG}$ concentrations $\left(\mathrm{r}=0.77 ; \mathrm{R}^{2}=0.59\right.$; $P<0.01)$.

In the present study, serum TP, Brix percentage, and IgG concentration as determined by RID were correlated $(\mathrm{r}=0.83$ and $\mathrm{r}=0.84$, respectively), consistent with previous studies (Calloway et al., 2002; Moore et al., 2009; Morrill et al., 2013; Deelen et al., 2014; Hernandez et al., 2016; Cuttance et al., 2017). We achieved a)
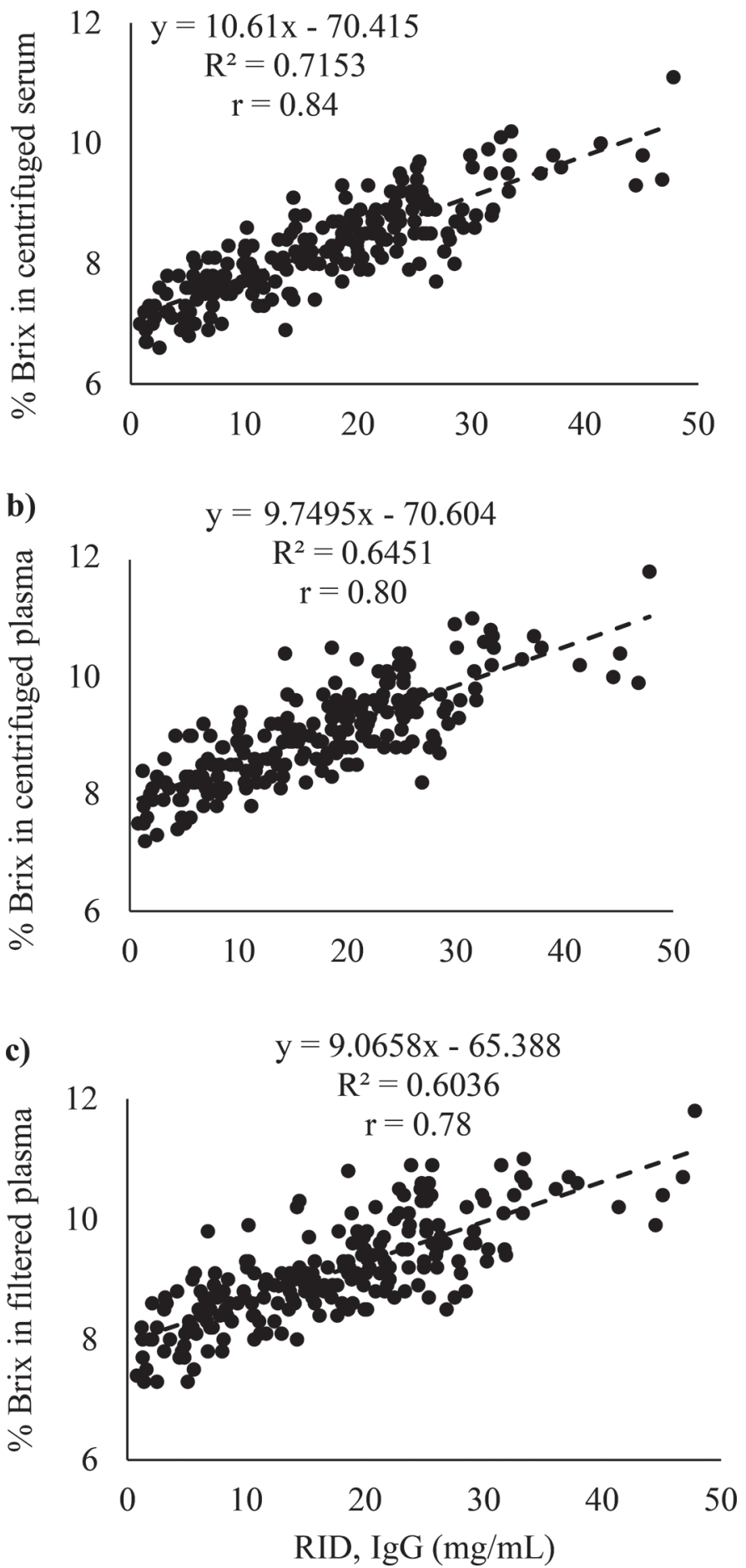

Figure 2. Concentration of $\operatorname{IgG}$ in the centrifuged serum of calves assessed with radial immunodiffusion (RID) compared with \% Brix in the (a) centrifuged serum $(\mathrm{n}=216 ; \mathrm{r}=0.84)$, (b) centrifuged plasma $(\mathrm{n}=216 ; \mathrm{r}=0.80$, and $(\mathrm{c})$ filtered plasma $(\mathrm{n}=216 ; \mathrm{r}=0.78)$ of calves using the Misco Brix refractometer (Misco, Solon, OH). 
a)

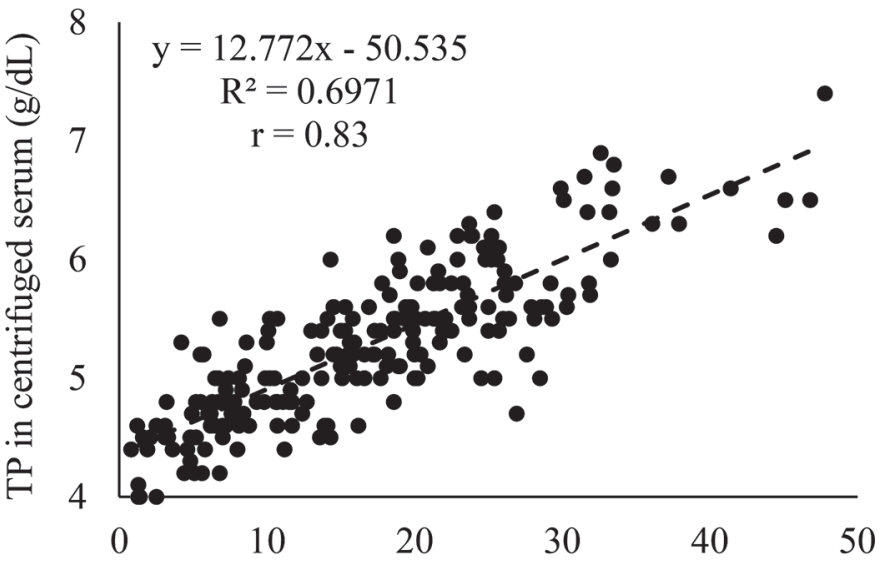

b)

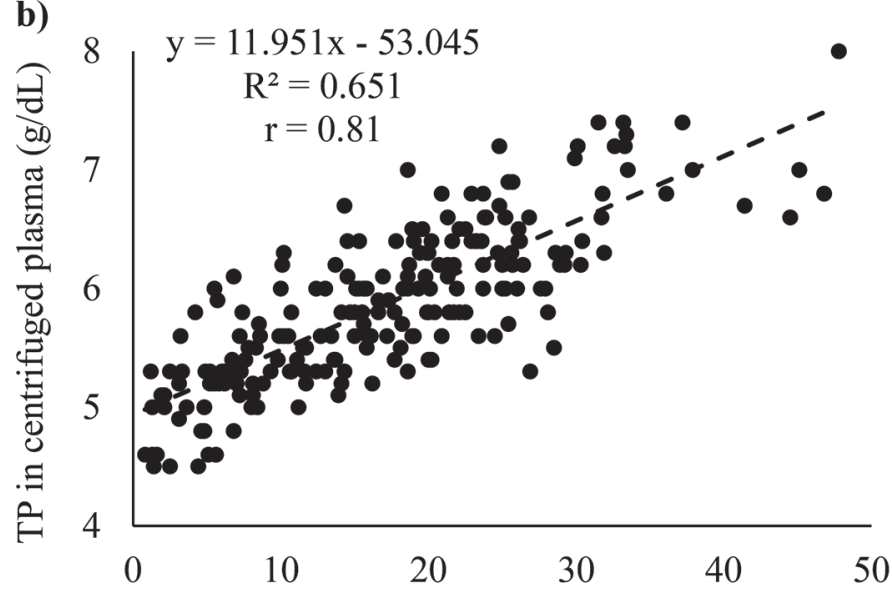

c)

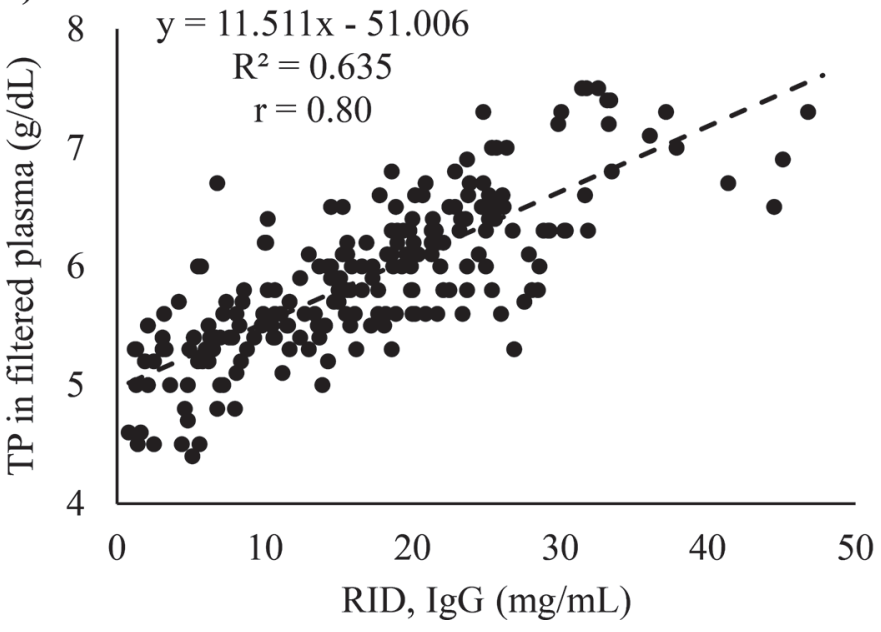

Figure 3. Concentration of IgG in the centrifuged serum of calves assessed with radial immunodiffusion (RID) compared with total protein (TP) concentration in the (a) centrifuged serum $(\mathrm{n}=216 ; \mathrm{r}=$ $0.83)$, (b) centrifuged plasma $(\mathrm{n}=216 ; \mathrm{r}=0.81)$, and (c) filtered plasma $(n=216 ; r=0.80)$ of calves using a handheld optical refractometer. comparable results with centrifuged $(\mathrm{r}=0.81$ and 0.80 , respectively) and filtered plasma $(\mathrm{r}=0.80$ and 0.78 , respectively). We also found a high correlation between the 3 different media (serum, centrifuged, and filtered plasma) using either the handheld optical refractometer or the digital Brix refractometer (range of correlation coefficients: $\mathrm{r}=0.92$ to 0.99 ). This finding confirmed that centrifuged and filtered plasma are suitable for
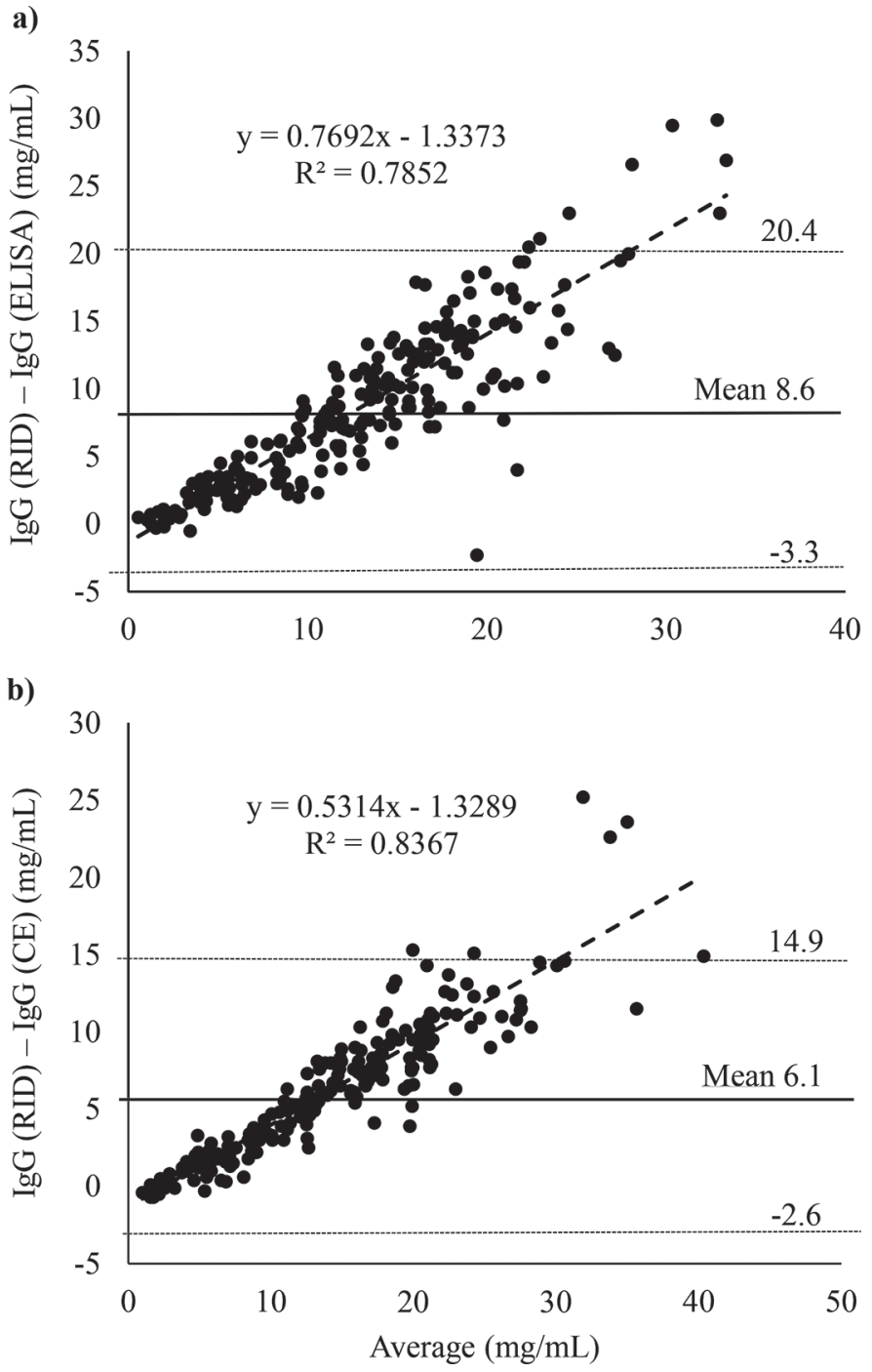

Figure 4. (a) Bland-Altman plot comparing measurement of IgG concentration in the serum of calves using radial immunodiffusion (RID) and ELISA. On average, the IgG concentration measured by RID was $8.6 \mathrm{mg} / \mathrm{mL}$ higher compared with ELISA. The limits of agreement were -3.3 and $20.4 \mathrm{mg} / \mathrm{mL}$ ( \pm 1.96 standard deviation; $95 \%$ confidence limit). (b) Bland-Altman plot comparing measurement of IgG concentration in the serum of calves using RID and capillary electrophoresis (CE). On average, the IgG concentration measured by RID was $6.1 \mathrm{mg} / \mathrm{mL}$ higher than that measured by CE. The limits of agreement were -2.6 and $14.9 \mathrm{mg} / \mathrm{mL}$ ( \pm 1.96 standard deviation; $95 \%$ confidence limit). 


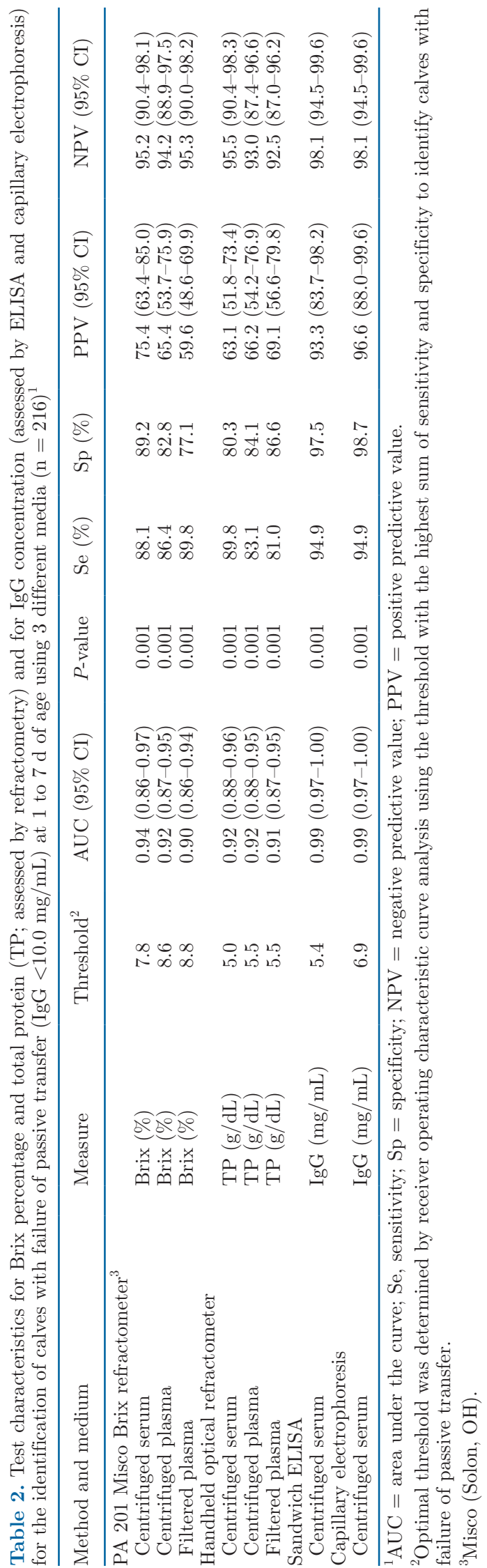

FPT assessment in calves, as suggested by da Costa Corrêa Oliveira et al. (2019).

The Bland-Altman plots illustrated a positive difference for both alternative laboratory methods (ELISA and $\mathrm{CE}$ ), indicating that results from these methods were lower than for RID (ELISA $8.6 \mathrm{mg} / \mathrm{mL}$; CE 6.1 $\mathrm{mg} / \mathrm{mL}$ ). Furthermore, the limits of agreement for both methods were wide (ELISA -3.3 and $20.4 \mathrm{mg} / \mathrm{mL}$; $\mathrm{CE}-2.6$ and $14.9 \mathrm{mg} / \mathrm{mL}$ ), because of a high mean difference and SD in both methods. The discrepancy between 2 measurements (RID and ELISA; RID and $\mathrm{CE}$ ) increased with concentration. Increased variability of the differences can often be observed with rising concentrations of the measured values (Grouven et al., 2007). The reason for this finding remains speculative. A direct quantitative comparison between RID and ELISA or CE is inadequate, but ELISA and CE allow for qualitative categorization (i.e., FPT vs. successful passive transfer) when their own specific cutpoints are used and can generate precise results for the assessment of FPT in neonatal calves.

\section{Test Characteristics}

The laboratory methods ELISA and CE were highly accurate $(0.9<\mathrm{AUC}<1)$ using $\mathrm{AUC}$ as an indicator of overall test characteristics (Swets, 1988). In both methods, the $95 \%$ CI overlapped, proving that the method was precise. We also detected high Se and Sp for both methods (ELISA: $\mathrm{Se}=94.9$ and $\mathrm{Sp}=97.5$; $\mathrm{CE}: \mathrm{Se}=94.9$ and $\mathrm{Sp}=98.7)$. The AUC results for the 2 on-farm tests also demonstrated high accuracy (0.9 $<$ AUC $<1$ ), irrespective of the medium used (Swets, 1988). Our findings were comparable to those of Lee et al. (2008), who compared direct and indirect methods for FPT assessment. In the present study, the 2 laboratory methods (CE and ELISA) were more accurate in identifying calves with FPT than the 2 on-farm devices, irrespective of the medium used. However, we found no difference in test accuracy among the laboratory methods and between the on-farm devices, because the $95 \%$ CI for the AUC overlapped. Studies using a handheld optical refractometer or a digital Brix refractometer to assess FPT in calves have reported similar overall test characteristics (Elsohaby et al., 2015; Hernandez et al., 2016; Cuttance et al., 2017; Buczinski et al., 2018).

Based on our results, the cutoff value for ELISA analysis with serum to identify calves with successful passive transfer should be $5.4 \mathrm{mg} \mathrm{IgG} / \mathrm{mL}$, and for CE analysis should be $6.9 \mathrm{mg} \mathrm{IgG} / \mathrm{mL}$. These are considerably below the cutoff value of $10 \mathrm{mg} / \mathrm{mL}$ when tested with RID (Tyler et al., 1996; Weaver et al., 2000; McGuirk and Collins, 2004; Godden, 2008). Both labora- 
tory methods had excellent test characteristics using these modified cutoff values.

The handheld optical refractometer and Brix refractometer on-farm tests revealed slightly lower cutoffs using serum $(5.0 \mathrm{~g} / \mathrm{dL}$ and $7.8 \%$ Brix $)$ than other studies (5.5 g/dL and 8.3\% Brix, Elsohaby et al., 2015; $5.2 \mathrm{~g} /$ $\mathrm{dL}$ and 8.5\% Brix, Hernandez et al., 2016; $5.2 \mathrm{~g} / \mathrm{dL}$ and $8.8 \%$ Brix, Cuttance et al., 2017). The reason for these differences remains speculative. These studies also used receiver operating characteristic curve analysis and serum IgG concentrations as assessed by RID (Elsohaby et al., 2015; Hernandez et al., 2016) or turbidimetric immunoassay (Cuttance et al., 2017) as references for determining the best threshold. The optimal thresholds for centrifuged and filtered plasma were higher than those for serum, irrespective of the device used (5.5 and $5.5 \mathrm{~g} / \mathrm{dL} ; 8.6$ and $8.8 \%$ Brix), comparable to the findings of the studies conducted by da Costa Corrêa Oliveira et al. (2019) and Elsohaby et al. (2019). Coagulation proteins such as fibrinogen are present in the plasma TP. These proteins are clotted during serum processing, leading to lower serum TP results (Lumeij and Maclean, 1996; George, 2001; da Costa Corrêa Oliveira et al., 2019; Elsohaby et al., 2019). Furthermore, plasma tubes contain anticoagulants such as lithium heparin, which can falsely increase plasma TP concentrations if the blood tubes are underfilled (Dubin and Hunt, 1978).

\section{Study Limitations}

Although RID is still the gold standard for FPT assessment and several authors have used it as the reference method for validation, this method has some limitations. Low antigen concentration can reduce accuracy, and uneven spread of the immunoprecipin ring diameters can confound results. To achieve comparable and reproducible results, the immunoprecipitin rings should be measured at exactly the same time (Varley et al., 1985). Evaluation of a new and potentially better test method can be only as good as the reference method.

\section{CONCLUSIONS}

All 4 analytical methods used in the present study were suitable for assessing FPT in neonatal calves, regardless of the medium used (i.e., centrifuged serum, centrifuged plasma, filtered plasma). These different analytical methods produced results that were highly correlated with RID (the gold standard) for assessing FPT in neonatal calves that were fed whole colostrum for first feeding. Different cutoff values must be con- sidered for the various analytical methods especially if different media are used. Serum and plasma can be used interchangeably when different cutoff values are considered. This study was the first to show that CE generates precise results for assessment of FPT in neonatal calves.

\section{ACKNOWLEDGMENTS}

We thank the participating dairy farms for their collaboration. We thank Pharmadoc (Lübeck, Germany) and TaiDoc (New Taipei City, Taiwan) for providing the plasma filters. Franziska Sutter was funded in part by Tiergyn e.V. (Berlin, Germany). The authors declare that they have no conflicts of interest.

\section{REFERENCES}

Barrington, G. M., and S. M. Parish. 2001. Bovine neonatal immunology. Vet. Clin. North Am. Food Anim. Pract. 17:463-476. https:/ /doi.org/10.1016/S0749-0720(15)30001-3.

Bennett, L. E., W. N. Charman, D. B. Williams, and S. A. Charman. 1994. Analysis of bovine immunoglobulin G by capillary gel electrophoresis. J. Pharm. Biomed. Anal. 12:1103-1108. https://doi .org/10.1016/0731-7085(94)E0037-2.

Besser, T. E., A. E. Garmedia, T. C. McGuire, and C. C. Gay. 1985. Effect of colostral immunoglobulin G1 and immunoglobulin M concentrations on immunoglobulin absorption in calves. J. Dairy Sci. 68:2033-2037. https://doi.org/10.3168/jds.S0022-0302(85)81065 $-1$.

Bielmann, V., J. Gillan, N. R. Perkins, A. L. Skidmore, S. Godden, and K. E. Leslie. 2010. An evaluation of Brix refractometry instruments for measurement of colostrum quality in dairy cattle. J. Dairy Sci. 93:3713-3721. https://doi.org/10.3168/jds.2009-2943.

Bland, J. M., and D. G. Altman. 1999. Measuring agreement in method comparison studies. Stat. Methods Med. Res. 8:135-160. https: //doi.org/10.1177/096228029900800204.

Bland, J. M., and D. G. Altman. 2003. Applying the right statistics: Analyses of measurement studies. Ultrasound Obstet. Gynecol. 22:85-93. https://doi.org/10.1002/uog.122.

Buczinski, S., E. Gicquel, G. Fecteau, Y. Takwoingi, M. Chigerwe, and J. M. Vandeweerd. 2018. Systematic review and meta-analysis of diagnostic accuracy of serum refractometry and Brix refractometry for the diagnosis of inadequate transfer of passive immunity in calves. J. Vet. Intern. Med. 32:474-483. https://doi.org/10.1111/ jvim. 14893.

Calloway, C. D., J. W. Tyler, R. K. Tessman, D. Hostetler, and J. Holle. 2002. Comparison of refractometers and test endpoints in the measurement of serum protein concentration to assess passive transfer status in calves. J. Am. Vet. Med. Assoc. 221:1605-1608. https://doi.org/10.2460/javma.2002.221.1605.

Chelack, B. J., P. S. Morley, and D. M. Haines. 1993. Evaluation of methods for dehydration of bovine colostrum for total replacement of normal colostrum in calves. Can. Vet. J. 34:407-412.

Chuck, G. M., P. D. Mansell, M. A. Stevenson, and M. M. Izzo. 2018. Early-life events associated with first-lactation performance in pasture-based dairy herds. J. Dairy Sci. 101:3488-3500. https:// doi.org/10.3168/jds.2017-12626.

Cuttance, E. L., W. A. Mason, K. S. Denholm, and R. A. Laven. 2017. Comparison of diagnostic tests for determining the prevalence of failure of passive transfer in New Zealand dairy calves. N. Z. Vet. J. 65:6-13. https://doi.org/10.1080/00480169.2016.1230525.

Cuttance, E. L., W. A. Mason, R. A. Laven, and C. V. C. Phyn. 2018. The relationship between failure of passive transfer and mortality, 
farmer-recorded animal health events and body weights of calves from birth until 12 months of age on pasture-based, seasonal calving dairy farms in New Zealand. Vet. J. 236:4-11. https://doi.org/ 10.1016/j.tvjl.2018.04.005.

da Costa Corrêa Oliveira, L., S. Borchardt, W. Heuwieser, E. Rauch, M. Erhard, and F. Sutter. 2019. Evaluation of a filter system to harvest plasma for identification of failure of passive transfer in newborn calves. J. Dairy Sci. 102:557-566. https://doi.org/10 $.3168 /$ jds.2018-15006.

Davis, R., and S. Giguère. 2005. Evaluation of five commercially available assays and measurement of serum total protein concentration via refractometry for the diagnosis of failure of passive transfer of immunity in foals. J. Am. Vet. Med. Assoc. 227:1640-1645. https: //doi.org/10.2460/javma.2005.227.1640.

Deelen, S. M., T. L. Ollivett, D. M. Haines, and K. E. Leslie. 2014. Evaluation of a Brix refractometer to estimate serum immunoglobulin G concentration in neonatal dairy calves. J. Dairy Sci. 97:3838-3844. https://doi.org/10.3168/jds.2014-7939.

Dubin, S., and P. Hunt. 1978. Effect of anticoagulants and glucose on refractometric estimation of protein in canine and rabbit plasma. Lab. Anim. Sci. 28:541-544.

Dunn, A., C. Duffy, A. Gordon, S. Morrison, A. Argüello, M. Welsh, and B. Earley. 2018. Comparison of single radial immunodiffusion and ELISA for the quantification of immunoglobulin $\mathrm{G}$ in bovine colostrum, milk and calf sera. J. Appl. Anim. Sci. 46:758-765. https://doi.org/10.1080/09712119.2017.1394860.

Elsohaby, I., J. T. McClure, and G. P. Keefe. 2015. Evaluation of digital and optical refractometers for assessing failure of transfer of passive immunity in dairy calves. J. Vet. Intern. Med. 29:721-726. https://doi.org/10.1111/jvim.12560.

Elsohaby, I., J. T. McClure, L. A. Waite, M. Cameron, L. C. Heider, and G. P. Keefe. 2019. Using serum and plasma samples to assess failure of transfer of passive immunity in dairy calves. J. Dairy Sci. 102:567-577. https://doi.org/10.3168/jds.2018-15070.

Erhard, M. H., P. Amon, S. Nüske, and M. Stangassinger. 1999. Studies on the systemic availability of maternal and endogeneously produced immunoglobulin G1 and G2 in newborn calves by using newly developed ELISA systems. J. Anim. Physiol. Anim. Nutr. (Berl.) 81:239-248

Faber, S. N., N. E. Faber, T. C. McCauley, and R. L. Ax. 2005. Case study: Effects of colostrum ingestion on lactational performance. Prof. Anim. Sci. 21:420-425. https://doi.org/10.15232/S1080 -7446(15)31240-7.

Gelsinger, S. L., A. M. Smith, C. M. Jones, and A. J. Heinrichs. 2015. Technical note: Comparison of radial immunodiffusion and ELISA for quantification of bovine immunoglobulin $\mathrm{G}$ in colostrum and plasma. J. Dairy Sci. 98:4084-4089. https://doi.org/10.3168/jds .2014-8491.

George, J. W. 2001. The usefulness and limitations of hand-held refractometers in veterinary laboratory medicine: An historical and technical review. Vet. Clin. Pathol. 30:201-210. https://doi.org/10 .1111/j.1939-165X.2001.tb00432.x.

Godden, S. 2008. Colostrum management for dairy calves. Vet. Clin. North Am. Food Anim. Pract. 24:19-39. https://doi.org/10.1016/ j.cvfa.2007.10.005.

Godden, S. 2017. Management of the newborn calf. Pages 399-408 in Large Dairy Herd Management. 3rd ed. D. K. Beede, ed. American Dairy Science Association, Champaign, IL.

Godden, S. M., D. M. Haines, K. Konkol, and J. Peterson. 2009. Improving passive transfer of immunoglobulins in calves. II: Interaction between feeding method and volume of colostrum fed. J. Dairy Sci. 92:1758-1764. https://doi.org/10.3168/jds.2008-1847.

Grouven, U., R. Bender, A. Ziegler, and S. Lange. 2007. Comparing methods of measurement. Dtsch. Med. Wochenschr. 132:e69-e73. [In German] https://doi.org/10.1055/s-2007-959047.

Hernandez, D., D. V. Nydam, S. M. Godden, L. S. Bristol, A. Kryzer, J. Ranum, and D. Schaefer. 2016. Brix refractometry in serum as a measure of failure of passive transfer compared to measured immunoglobulin $\mathrm{G}$ and total protein by refractometry in serum from dairy calves. Vet. J. 211:82-87. https://doi.org/10.1016/j.tvjl.2015 .11 .004 .
Hogan, I., M. Doherty, J. Fagan, E. Kennedy, M. Conneely, P. Brady, C. Ryan, and I. Lorenz. 2015. Comparison of rapid laboratory tests for failure of passive transfer in the bovine. Ir. Vet. J. 68:18. https://doi.org/10.1186/s13620-015-0047-0.

Kertz, A. F., T. M. Hill, J. D. Quigley III, A. J. Heinrichs, J. G. Linn, and J. K. Drackley. 2017. A 100-year review: Calf nutrition and management. J. Dairy Sci. 100:10151-10172. https://doi.org/10 .3168/jds.2017-13062.

Lee, S. H., J. Jaekal, C. S. Bae, B. H. Chung, S. C. Yun, M. J. Gwak, G. J. Noh, and D. H. Lee. 2008. Enzyme-linked immunosorbent assay, single radial immunodiffusion, and indirect methods for the detection of failure of transfer of passive immunity in dairy calves. J. Vet. Intern. Med. 22:212-218. https://doi.org/10.1111/j.1939 $-1676.2007 .0013 . x$.

Lora, I., F. Gottardo, B. Contiero, B. Dall Ava, L. Bonfanti, A. Stefani, and A. Barberio. 2018. Association between passive immunity and health status of dairy calves under 30 days of age. Prev. Vet. Med. 152:12-15. https://doi.org/10.1016/j.prevetmed.2018.01.009.

Lumeij, J. T., and B. Maclean. 1996. Total protein determination in pigeon plasma and serum: Comparison of refractometric methods with the biuret method. J. Avian Med. Surg. 10:150-152

MacFarlane, J. A., D. H. Grove-White, M. D. Royal, and R. F. Smith. 2014. Use of plasma samples to assess passive transfer in calves using refractometry: Comparison with serum and clinical cut-off point. Vet. Rec. 174:303. https://doi.org/10.1136/vr.102228.

McCracken, M. M., K. M. Morrill, A. L. Fordyce, and H. D. Tyler. 2017. Technical note: Evaluation of digital refractometers to estimate serum immunoglobulin G concentration and passive transfer in Jersey calves. J. Dairy Sci. 100:8438-8442. https://doi.org/10 $.3168 /$ jds.2017-12847.

McGuirk, S. M., and M. Collins. 2004. Managing the production, storage, and delivery of colostrum. Vet. Clin. North Am. Food Anim. Pract. 20:593-603. https://doi.org/10.1016/j.cvfa.2004.06.005.

Moinester, M., and R. Gottfried. 2014. Sample size estimation for correlations with pre-specified confidence interval. Quant. Methods Psychol. 10:124-130. https://doi.org/10.20982/tqmp.10.2.p0124.

Mokhber-Dezfooli, M. R., M. Nouri, M. Rasekh, and P. D. Constable. 2012. Effect of abomasal emptying rate on the apparent efficiency of colostral immunoglobulin G absorption in neonatal HolsteinFriesian calves. J. Dairy Sci. 95:6740-6749. https://doi.org/10 $.3168 /$ jds.2012-5926.

Moore, D. A., J. Taylor, M. L. Hartman, and W. M. Sischo. 2009. Quality assessments of waste milk at a calf ranch. J. Dairy Sci 92:3503-3509. https://doi.org/10.3168/jds.2008-1623.

Morrill, K. M., J. Polo, A. Lago, J. Campbell, J. Quigley, and H. Tyler. 2013. Estimate of serum immunoglobulin G concentration using refractometry with or without caprylic acid fractionation. J. Dairy Sci. 96:4535-4541. https://doi.org/10.3168/jds.2012-5843.

Pritchett, L. C., C. C. Gay, T. E. Besser, and D. D. Hancock. 1991 Management and production factors influencing immunoglobulin G1 concentration in colostrum from Holstein cows. J. Dairy Sci. 74:2336-2341. https://doi.org/10.3168/jds.S0022-0302(91)78406 -3 .

Rajala, P., and H. Castren. 1995. Serum immunoglobulin concentrations and health of dairy calves in two management systems from birth to 12 weeks of age. J. Dairy Sci. 78:2737-2744. https://doi .org/10.3168/jds.S0022-0302(95)76904-1.

Soberon, F., E. Raffrenato, R. W. Everett, and M. E. Van Amburgh. 2012. Preweaning milk replacer intake and effects on long-term productivity of dairy calves. J. Dairy Sci. 95:783-793. https://doi .org/10.3168/jds.2011-4391.

Soberon, F., and M. E. Van Amburgh. 2013. Lactation Biology Symposium: The effect of nutrient intake from milk or milk replacer of preweaned dairy calves on lactation milk yield as adults: A meta-analysis of current data. J. Anim. Sci. 91:706-712. https:// doi.org/10.2527/jas.2012-5834.

Stott, G. H., D. B. Marx, B. E. Menefee, and G. T. Nightengale. 1979a. Colostral immunoglobulin transfer in calves I. Period of absorption. J. Dairy Sci. 62:1632-1638. https://doi.org/10.3168/ jds.S0022-0302(79)83472-4. 
Stott, G. H., D. B. Marx, B. E. Menefee, and G. T. Nightengale. 1979b. Colostral immunoglobulin transfer in calves. III. Amount of absorption. J. Dairy Sci. 62:1902-1907. https://doi.org/10.3168/ jds.S0022-0302(79)83521-3.

Swets, J. A. 1988. Measuring the accuracy of diagnostic systems. Science 240:1285-1293. https://doi.org/10.1126/science.3287615.

Tyler, J. W., D. D. Hancock, S. M. Parish, D. E. Rea, T. E. Besser, S. G. Sanders, and L. K. Wilson. 1996. Evaluation of 3 assays for failure of passive transfer in calves. J. Vet. Intern. Med. 10:304-307. https://doi.org/10.1111/j.1939-1676.1996.tb02067.x.

Varley, M. A., G. J. Rucklidge, R. J. Wilkinson, and A. Maitland. 1985. Enzyme-linked immunosorbent assay for the measurement of immunoglobulin $\mathrm{G}$ concentrations in porcine plasma and colostrum. Res. Vet. Sci. 38:279-281. https://doi.org/10.1016/S0034 -5288(18)31794-6.

Villarroel, A., T. B. Miller, J. K. Ward, E. D. Johnson, and K. R. Noyes. 2014. Differences in total protein concentration between fresh and frozen serum and plasma samples used to assess failure of passive transfer in dairy calves. J. Adv. Dairy Res. 2:1-5.
Weaver, D. M., J. W. Tyler, D. C. VanMetre, D. E. Hostetler, and G. M. Barrington. 2000. Passive transfer of colostral immunoglobulins in calves. J. Vet. Intern. Med. 14:569-577. https://doi.org/10 $.1111 /$ j.1939-1676.2000.tb02278.x.

Zhu, Z., J. J. Lu, and S. Liu. 2012. Protein separation by capillary gel electrophoresis: A review. Anal. Chim. Acta 709:21-31. https://doi .org/10.1016/j.aca.2011.10.022.

\section{ORCIDS}

E. Rauch ๑ https://orcid.org/0000-0001-9992-3902

C. Weber (1) https://orcid.org/0000-0003-4858-2188

W. Heuwieser @ https://orcid.org/0000-0003-1434-7083

S. Borchardt (1) https://orcid.org/0000-0003-3937-5777 